DOI 10.15593/2224-9354/2017.3.25

УДК 330.341.1 (470+571)

\title{
И.А. Сушкова
}

\section{НЕОИНДУСТРИАЛИЗАЦИЯ РОССИИ: ВНУТРЕННИЕ БАРЬЕРЫ НА ПУТИ ЕЕ ОСУЩЕСТВЛЕНИЯ}

\begin{abstract}
Обосновывается необходимость неоиндустриализации экономики России. Рассмотрены внутренние барьеры на пути неоиндустриализации, которые, прежде всего, обусловлены состоянием производительных сил и производственных отношений в стране. Успешность решения поставленных задач зависит от правильности принимаемых решений, способов их реализации, от адекватности подходов к формированию нового, неоиндустриального порядка.

Автор считает, что выстраивание новой модели развития предполагает незамедлительное принятие и исполнение политики неоиндустриализации. В статье дается понятие, выделяется цель, раскрывается суть политики неоиндустриализации, а также анализируются условия и тенденции реализации политики неоиндустриальных преобразований.

В результате анализа автор приходит к выводу о необходимости ускорения перехода на новую модель народно-хозяйственного планирования и повышения качества корпоративного управления. Необходимо повышение эффективности производства, усиление роли государства на рынках и в производстве, а также в формировании и организации направлений движения денежных потоков на развитие промышленного сектора экономики.

Для реализации процесса неоиндустриализации необходим переход к инновационному типу экономического развития страны. А это, в свою очередь, требует новых организационных и хозяйственных форм и методов управления инновационной деятельностью. Преодоление барьеров неоиндустриализации предполагает решительное изменение отношения со стороны правительства к сохранению и преумножению интеллектуальных ресурсов.

Автор пришел к выводу, что последовательное проведение такой политики достигается путем разрешения возникающих противоречий между государственными институтами и самостоятельно хозяйствующими предприятиями и считает, что в России имеются все предпосылки для реализации политики преодоления барьеров неоиндустриализации экономики.

Ключевые слова: неоиндустриализация, политики неоиндустриализации, производительность труда, государственная промышленная политика, индустриальное развитие, инвестиции, инновационный тип экономического роста, инновационная деятельность, корпоративное управление, интеллектуальные ресурсы, человеческий потенциал, национальный капитал, фринансовые потоки, неоиндустриальные преобразования, новая модель экономики.
\end{abstract}

Россия пережила за свою историю немало катастроф и преодолела бесчисленное количество преград. В период ключевых и переломных изменений всегда возникает множество проблем при их протекании. В последние годы к уже имеющимся немалым внутренним экономическим и социальным проблемам присоединились внешнеполитические, вновь сложившиеся немалые трудности, возникшие в связи с конкретной однополярной глобализацией и поддержанной в Европе американской пропагандой абстрактных свобод и демократий.

(C) Сушкова И.А., 2017

Сушкова Ирина Алексеевна - канд. экон. наук, доцент кафедры экономической безопасности ФГБОУ ВО «Саратовский социально-экономический институт (филиал) РЭУ им. Г.В. Плеханова», e-mail: irinasushkova60@ mail.ru. 
«Как научная категория новая индустриализация означает прогрессивное изменение средств производства - их обновление и усовершенствование на основе нового знания и в соответствии с прорывными технологиями и стандартами. Как экономическая категория новая индустриализация выражает отношения, складывающиеся между людьми по поводу производства, использования технически и технологически новых средств производства и присвоения результатов их функционирования» [1, с. 94].

«Механизм неоиндустриализации - это механизм инновационно ориентированного развития социально-экономической системы. Формируется механизм неоиндустриализации в ответ на запрос самой экономической системы, постепенно, по мере ее развития» [2, с. 660].

Внутренние барьеры на пути неоиндустриализации обусловлены состоянием производительных сил и производственных отношений в стране. «Осуществление процесса неоиндустриализации производительных сил определяется: исходным физическим ресурсом; технологиями; знаниями и способностями агентов, их уровнем образования, здоровья; стимулами к преобразовательной деятельности; состоянием и тенденциями развития производственных систем и производительных сил общества» [3, с. 76]. России предстоит решать вопросы выстраивания структурно-диверсифицированной экономики, выведения ее из-под зависимости от внешних конъюнктурных факторов и спекулятивного иностранного капитала, принятия новой формулы развития народного хозяйства и введения в действие внутренних ресурсных источников его обеспечения. «...В новой модели хозяйствования должны быть задействованы такие способы организации хозяйственных связей, такие формы собственности и такое их соотношение, которые способствовали бы использованию плановых начал в механизме хозяйствования, вели к обобществлению и централизации производительных сил...» [4, с. 139]. Успешность решения этих задач всецело зависит от правильности принятых решений, от выбора способов их реализации, от адекватности подходов к формированию нового неоиндустриального порядка. На этом пути предстоит сделать непростой выбор из предлагаемых альтернативных моделей развития, моделей политики, стратегии, форм модернизации российской экономики, преодолеть множество сложившихся противоречий при выборе модели устойчивого экономического роста, установлении предпочтений альтернатив долгосрочного экономического развития в рамках существующей политико-экономической модели российского общества.

На сегодняшний день экономическая наука предлагает множество моделей реформирования существующей социально-экономической системы, сложились альтернативные подходы в анализе экономической политики, поразному оценивается доля государства в российской экономике. Взамен модели экономики спроса, допускающей избыточное присутствие государства, предлагается модель экономики предложения, по которой предпочтительным 
признается открытость экономики, стимулирование внутренней конкуренции, последовательное проведение приватизации, формирование широкого слоя среднего и крупного бизнеса, привлечение стратегических инвесторов. Необходимо отметить, что «при осуществлении модернизации основной акцент нужно сделать не только (и даже не столько) на темпах роста, сколько на его качестве. Потребуется выработать новую модель роста, основанную на стимулировании предложения товаров и услуг, т.е. на создании условий для успешного функционирования и развития экономических агентов» [5, с. 20]. Наметившиеся в экономической науке теоретические выводы и имеющиеся эмпирические данные свидетельствуют о том, что выстраивание новой модели развития с неизбежностью предполагает незамедлительное принятие и исполнение политики неоиндустриализации. «В процессе формирования новой модели экономического развития, способной обеспечить новую индустриализацию российской экономики и устойчивый экономический рост, происходит создание основ формирования неоиндустриальной политики» [6, с. 103].

Политика неоиндустриализации - определенный этап развития экономической политики государства, обусловленный масштабностью стратегических задач развития социально-экономической системы страны. Она направлена на реализацию инновационных перемен в производительных силах и производственных отношениях, генерацию научно-исследовательской среды, обеспечивающей преумножение фундаментальных и прикладных знаний, формирование инновационного мировоззрения общества. Политика неоиндустриализации определяет вектор развития экономики и общества в целом, предопределяющий модернизацию общества на основе высоких технологий, концентрации ресурсов в наукоемких производственных секторах и использования самых современных научно-технических достижений. Такая политика выступает организатором планового установления прогрессивной индустриально-технологической структуры экономики и стратегического управления прогрессивного развития страны.

По своей сути политика неоиндустриализации представляется как взаимодействие предпринимаемых на национально-государственном уровне согласованных экономических, политических и социальных мер, обеспечивающих формирование нового индустриального порядка хозяйствования, устойчивую динамику его формирования, ускоренные темпы движения и ожидаемые результаты осуществления с использованием соответствующего набора необходимых, наиболее действенных стимулов и инструментов.

«Исследование условий и тенденций реализации политики обеспечения перехода России на неоиндустриальный путь развития - проблема достаточно сложная и широкая. Она включает глубокое теоретическое освоение экономического смысла самой политики неоиндустриализации, выявление ее возможностей придания системности, комплексности, логической завершен- 
ности процессу перехода на путь неоиндустриальных преобразований страны, выделение противоречивых тенденций и условий дальнейшего развития объекта воздействия этой политики. Одной из наиболее важных является проблема преодоления барьеров на пути реализации неоиндустриальной политики, претворения в жизнь решений, направленных на ее осуществление» [7, с. 127].

Практика хозяйствования свидетельствует о том, что и модель спроса, и модель предложения не являются безупречными. И та и другая не отражают взаимодействия материально-вещественных и стоимостных рыночных элементов [8, с. 12], что усложняет выбор вариантов политики неоиндустриализации, определения материальных ресурсов ее реализации. Кроме того, на выбор вариантов политики неоиндустриализации негативное воздействие оказывает внутренний рынок, который при достаточно большом потенциале имеет малые фактические размеры и слабые рыночные импульсы к развитию производства, расширению инвестирования. По оценке многих экспертов, российская экономика пока еще «недостаточно рыночная».

В сложных внутренних условиях и при наличии санкций обеспечение перехода на путь неоиндустриального развития диктует необходимость принятия срочных мер по преодолению инерции экономики, переориентации с сырьевого на технологическое развитие, кардинальному увеличению агрегированного мультипликатора добавленной стоимости. Страна стоит перед непростым выбором: предстоит разумно распределять ограниченные ресурсы между секторами, обеспечивающими текущее потребление большинства населения, потребности научного, технико-технологического развития и укрепления национальной безопасности. На этом пути есть немало сложностей. И ученые, и эксперты предупреждают об усилении противоречивых тенденций в экономике и возрастании рисков будущего ее развития, если допустить нарушение соответствия объемов используемых доходов по этим секторам. Вместе с тем решение конкретных проблем по преодолению сложившихся системных проблем, вызовов стадиального регресса в России осложнено отсутствием базиса неоиндустриального развития, базиса будущей неоиндустриальной экономики - экономики более высокого порядка, более высокой стадии развития. Таковым является более высокая производительность труда и увеличивающаяся покупательная способность населения страны. «Нечто иное, кроме производительности труда, в исторически-формационный зачет не идет и не принимается: более передовым признается только тот строй, который не на словах, а на деле обеспечивает исторически высшую производительность труда непосредственных работников. Все остальные моменты, насколько бы важными они ни казались, по сравнению с данным обобщенным критерием выступают производными и второстепенными» [9, с. 9].

Признавая всю важность выделенных проблем, отметим, что главная цель политики неоиндустриализации - создание базиса новой экономической системы, соответствующей государственно-кооперативной стадии развития. 
Главными барьерами на пути формирования такой экономики становятся:

• недостаточная по уровню развития производительность общественного труда;

- низкая покупательная способность;

- зависимость внутренних цен и ценообразования от валютного курса рубля и мировой цены на нефть;

• медленный переход на новую модель народно-хозяйственного планирования.

Преодоление этих барьеров потребует немало усилий. И, тем не менее, их придется преодолевать. При оценке воздействия этих факторов на экономику требуется учитывать сложившиеся обстоятельства. Перечисленные факторы характерны для российской экономики как объективно сложившиеся, и они преодолеваются постепенно в ходе ее развития. Сейчас в условиях экономических санкций ряд факторов усиливают свое воздействие на экономику. Так, курс рубля ускоряет темпы своего падения и его все более считают привязанным к ценам на нефть. По мнению ряда экспертов такой прямой зависимости здесь нет. Речь скорее идет о бесконтрольности рынка со стороны властей. Как бы не оценивать эти факторы, их дальнейшее действие грозит экономической дестабилизацией для России. В таких некомфортных условиях для российской экономики нельзя допустить разбалансированность валютного рынка и быстрые темпы роста курса иностранных валют. Требуется четкий и постоянный контроль над курсом рубля со стороны Центрального банка и Правительства России, а при необходимости - принятие жестких мер.

Кроме актуальных и достаточно срочных вопросов валютного рынка российской власти предстоит решать и далее вопросы экономического развития. Главное, на что должны быть направлены усилия государства, это безотлагательное принятие мер по росту производительности общественного труда. Прежде всего, темпы роста производительности труда должны быть строго контролируемы, поскольку именно производительность труда определяет такие важные показатели, как доля внутреннего накопления, окупаемость капитальных вложений и уровень жизни населения. Кроме того, именно уровень производительности труда необходимо принять в качестве определяющего критерия при формировании планово-экономической модели снижения народно-хозяйственных издержек.

Пора ускорить переход на новую модель народно-хозяйственного планирования и повышать качество корпоративного управления. Четкое соединение макроэкономического и корпоративного планирования и управления является составной частью механизма реализации неоиндустриальных преобразований и важнейшим структурным элементом новой экономической политики. Неоиндустриальная экономика - это экономика крупных отечественных транснациональных корпораций. И то, как обстоит дело в корпора- 
тивном управлении, в его взаимосвязи с управлением государственным, во многом определяет не только эффективность развития отдельной компании, но и направленность реализации новой экономической политики, вектор движения всей экономики. Снижение высоких страновых рисков опосредуется реальной оценкой российских компаний и уровня рисковости корпоративного управления.

Народно-хозяйственные планы перехода к новой модели экономики должны включать превращение крупных российских промышленных корпораций в основные источники и локомотивы роста, в главную опору безболезненного обновления структуры нашей экономики. Предстоит задействовать корпорации тех отраслей промышленности, которые являются на сегодняшний день наиболее развитыми и высокотехнологичными, к примеру, атомная и авиационная. Совместные меры народно-хозяйственного планирования и корпоративного управления, направленные на развитие обрабатывающей промышленности, станкостроения и приборостроения, позволят превратить процесс обновления экономики в поступательный процесс. Вместе с тем нельзя исключать участия в этом процессе малых и средних промышленных предприятий, источником финансирования которых становится частный капитал. Поэтому в число приоритетов новой государственной промышленной политики включается поддержка предпринимательской активности и поддержка частного бизнеса, расширения его возможностей на ресурсных рынках.

Ускоренного индустриального развития стоит добиваться повышением эффективности производства, умелым усилением роли государства на рынках и в производстве. «Сторонники теории государства развития исходят из того, что богатство нации формируется посредством ограниченной конкуренции, создающей индустриальную ренту, которая должна делиться между капиталистами (более высокие прибыли), работниками (более высокие зарплаты) и государством (более высокие налоги)» [7, с. 133]. Неоценимую роль при этом играет политика протекционизма. Классическая экономическая наука считает возможным полагаться на рынок и рыночную конкуренцию только в том случае, если это не противоречит основной государственной задаче в сфере модернизации экономики. России, преодолевающей экспортную зависимость, предстоит осуществить национальную индустриализацию на основе промышленной политики и государственного индустриального протекционизма. На этом направлении предстоит диверсифицировать структуру национального производства, поощряя отрасли с большим потенциалом для технологического переоснащения и, следовательно, понижая стоимость производства единицы продукции, создавая производственные цепочки между отраслями и регионами страны. Здесь важна доля участия государства в формировании и организации направлений движения денежных потоков на развитие промышленного сектора экономики. Но решить эту проблему, ис- 
пользуя только бюджетное финансирование, весьма трудно в силу ограниченности государственных ресурсов. Вместе с тем промышленный сектор экономики - сектор высокорисковый, с большим сроком окупаемости проектов. Нужны стимулирующие меры для вовлечения банков в систему кредитования, активного привлечения частных инвестиций. Решать эти проблемы возможно путем создания совместных предприятий, и на уровне государства, и на уровне частного бизнеса, что, как правило, становится отправной точкой для дальнейшего развития. А привлечение прямых иностранных инвестиций и партнеров обеспечивает создание дополнительного количества рабочих мест, и привносит в российскую промышленность новые технологии и знания.

Для активизации финансовых потоков банковскому сектору предстоит стать реальным инвестором при поддержке системы налогообложения. Пока же в России коммерческие банки не имеют возможности предоставления кредитов с меньшими процентами по отношению к ключевой ставке или уровню инфляции, а о сокращении до приемлемого уровня налогового бремени для индустриальных предприятий тоже пока речь не идет. Потому создание комфортных условий для развития новых промышленных высокотехнологичных предприятий пока остается весьма затруднительным. Им нужны средства на обновление основных фондов. На эти цели, «по оценкам Министерства финансов РФ, промышленным предприятиям сегодня необходимо тратить около $30 \%$ ВВП в год, а 70 \% всех инвестиций в перевооружение производства вкладывают сами предприятия, откладывая проекты по развитию и расширению в долгий ящик. Банковский сектор, переживает не лучшие времена. При нынешней ситуации на рынках он не способен в должной мере обеспечивать деньгами российскую промышленность, что способствует резкому повышению рисков в долгосрочном периоде» [7, с. 135].

При всех изменениях в политике ЦБ РФ необходимы решительные меры, обеспечивающие доступность кредита для обрабатывающей промышленности, что уменьшит для предприятий капитальные затраты, и приемлемый уровень ставки по ипотеке, чтобы не обрушить строительную отрасль и не увеличить количество обманутого населения. Понятно, что власть старается минимизировать риски через сбалансированность финансовой сферы. Политической целью реально становится создание сильного национального капитала, который при первой неблагоприятной ситуации не бежит из страны, а воспринимает ее как базу для развития и защиты. Только национальный капитал становится надежным партнером государству в реализации крупных проектов развития. При этом он должен включать в себя, кроме сырьевых или полусырьевых контролируемых государством компаний, и множество средних компаний. Направленность финансовых потоков этих компаний на проведение реиндустриализации и неоиндустриализации является необходимым условием развития национальной промышленности и сельского хозяй- 
ства страны. Однако в действительности национальный капитал пока работает, прежде всего, на свой собственный интерес. Собственным интересом объясняется направленность его денежных потоков и, как оказывается, не в сторону и не в пользу собственной экономики. Повернуть денежные потоки в нужном направлении можно через предоставление возможности региональным банкам кредитовать средний бизнес, поощрение их активности на фондовом рынке, вменение в обязанность крупным банкам с государственным участием выкупать часть облигационных займов, размещаемых региональными банками.

Ближайшая перспектива развития экономики России связана с необходимостью инновационного развития [10, с.60]. В сложных социальноэкономических системах реализация процесса неоиндустриализации требует новых организационных и хозяйственных форм и методов управления инновационной деятельностью, которые способны обеспечить переход к инновационному типу экономического роста. «...Новый уровень инновационного развития предполагает форму неоиндустриализации, заключающуюся в восстановлении обрабатывающей промышленности на новой технологической основе и развитие высокотехнологического сектора нематериальных производств» $[11$, с. 60]. В рамках таких форм хозяйствующие агенты инновационной ориентации приобретают опыт реальной оценки последствий нового технологического сдвига, прогнозирования будущих барьеров эффективности применяемой технологии, организации движения в рыночных условиях потоков своих капиталов и ресурсов. Кроме того, рынок постоянно детерминирует планы инновационной деятельности в производстве, предопределяя принятие новых решений в области инноваций, а также необходимость выбора из альтернативных вариантов конкретного инновационного проекта, изменения сроков его осуществления, использования и замены его новым. «Несомненно, необходимо поддержать инноваторов для повышения конкурентоспособности технологий, проектов, продукции, а также имиджа...» [12, с. 20]. Следует отметить, что «развитие и расширение инновационной активности являются ядром экономической политики любой экономически развитой страны» $[13$, с. 86].

Преодоление барьеров неоиндустриализации предполагает решительное изменение отношения со стороны правительства к сохранению и преумножению интеллектуальных ресурсов, поскольку отечественный человеческий потенциал является важным условием и источником неоиндустриальных преобразований. «...С формированием инновационного типа экономики России, особое внимание уделяется развитию новых институтов, созданию современной инфраструктуры, внедрению инноваций на всех уровнях хозяйствования, вложению инвестиций в человеческий капитал, выделению в качестве приоритетов знаний и высококвалифицированного интеллектуального труда, создающего наибольшую добавленную стоимость» $[14$, с. 15$]$. 
Персонификация субъектов процесса неоиндустриализации, учет приоритетности интересов лучших специалистов технических сфер, открывателей нового в микробиологии и генетике, создателей мировых шедевров в гуманитарных областях, новаторов в системе управления в совокупности с учетом общественного интереса, аккумулируют стимулы к развитию, к организации работы на общую идею, на благо нации. При сочетании и адекватном соотношении всех групп интересов формируются возможности смягчения противоречивых тенденций в процессе реализации неоиндустриальных преобразований, так как сама идея неоиндустриализации становится общей для хозяйственного субъекта, отдельной личности, нации. В частности, можно подчеркнуть, что «предприятия, ориентированные на долгосрочный устойчивый рост, достигают цели только за счет привлечения и удержания высококлассных работников... Текущее повышение квалификации, приобретение новых знаний и навыков для трудовой деятельности в будущем способствует росту человеческого капитала, что формирует высокий интеллектуальный потенциал предприятия» [15, с. 44].

«В персонификации субъектов процесса неоиндустриализации определяющим является разделения труда между ними и установление прав собственности на результаты их деятельности. Созданное новшество передается внешнему потребителю путем непосредственной продажи либо используется внутри фирмы, приводя к сокращению затрат на изготовление продукции. Благодаря этому в инновационном процессе реализуются экономические отношения между создателями новшеств, собственниками ресурсов и потребителями новой продукции. Экономические интересы участников этого процесса предопределяют численность привлеченных работников, выбор организационно-правовых структур, систему управления. Заинтересованность хозяйствующих субъектов в инновационной деятельности обусловлена получаемым эффектом от ее конечных результатов, т.е. от величины будущей прибыли, связанной с реализацией новшества. Конечный результат напрямую зависит от ресурсных возможностей обеспечения инновационной деятельности, которая является основой создания, производства и реализации новшеств. Поэтому политика преодоления барьеров неоиндустриализации призвана обеспечить тесную корреляцию между технико-технологическим состоянием производства, масштабом стоящих перед ним практических задач и возможностями их решения» [7, с. 144].

Последовательное проведение такой политики достигается путем разрешения противоречий, возникающих между институтами государства, которые обеспечивают реализацию интересов общества, и самостоятельно хозяйствующими предприятиями, наиболее полно проявляющими взаимодействие коллективных и личных интересов работников предприятий. Безусловно, характер отмеченного противоречия определяется отраслевыми особенностями, 
реальностью целевых установок, уровнем развития национальной экономики, зрелостью социально-политической системы. Разрешение данного противоречия возможно при наиболее рациональном соотношении между процессом инновационно-интеграционного развития экономики и процессом оптимального участия государства в организации такого процесса. В ходе разрешения этого противоречия через хозяйственный механизм обеспечивается возможность самоорганизации и эффективного саморазвития промышленных предприятий, а власти могут стимулировать стремление субъектов к инновациям, к увеличению темпов кооперации собственности и промышленных капиталов в расчете на крупномасштабное увеличение затрат при переоснащении производства.

В России имеются все предпосылки для реализации политики преодоления барьеров неоиндустриализации. Выгодное географическое положение дает России выход на наиболее динамично развивающиеся азиатские рынки. Богатство дешевых энергетических ресурсов обеспечивает России ключевую роль при неоиндустриализации экономики. Успех политики преодоления барьеров неоиндустриализации обеспечивается решительностью государства, его активными координационными действиями, принятием стимулирующих мер и обоснованным выбором основных приоритетов при реализации курса развития, что способствует консолидации интересов участников процесса неоиндустриального развития российской экономики.

\section{Список литературы}

1. Сушкова И.А. Новая индустриализация национальной экономики: понятие, условия, подходы // Вестник Саратовского госагроуниверситета им. Н.И. Вавилова. - 2014. - № 4. - С. 93-97.

2. Сушкова И.А. Механизм неоиндустриализации: методология обоснования // Известия Саратовского университета. Новая серия. Экономика. Управление. Право. - 2013. - Т. 13, вып. 4, ч. 2. - С. 656-661.

3. Сушкова И.А. Формирование инновационного воспроизводства - признак и условие новой индустриализации // Инновационная деятельность. 2013. - № 4 (27). - С. 73-79.

4. Сушкова И.А. Предпосылки формирования политики неоиндустриализации // Философия хозяйства. Альманах Центра общественных наук и экономического факультета МГУ им. М.В. Ломоносова. - 2014. - № 6 (96). С. $139-148$.

5. Мау В. Экономическая политика 2010 года: в поисках инноваций // Вопросы экономики. - 2011. - № 2. - С. 4-22.

6. Сушкова И.А. Переход к новой модели экономического развития основа формирования политики неоиндустриализации // Предпринимательство. - 2014. - № 2. - С. 94-103. 
7. Сушкова И.А. Неоиндустриальная политика: основы формирования, факторы развития. - Саратов: Наука, 2013. - 238 с.

8. Плышевский Б. Об «экономике предложения» (ее идейные основы и цели) // Экономист. - 2012. - № 7. - С. 3-15.

9. Губанов С. Неоиндустриализация России и нищета ее саботажной критики // Экономист. - 2014. - № 4. - С. 3-32.

10. Мамаева Л.Н. Инновационное предпринимательство в России в условиях санкций // Вестник Тверского гос. университета. Экономика и управление. - 2015. - № 4. - С. 59-64.

11. Сушкова И.А. Принципы и проблемы неоиндустриального преобразования российской экономики // Информационная безопасность регионов. 2015. - № 4 (21). - С. 67-75.

12. Мамаева Л.Н. Инвестиционная привлекательность Саратовской области // Наука и общество. - 2014. - № 4 (19). - С. 17-20.

13. Сушкова И.А. Инновационное воспроизводство как объективная необходимость неоиндустриализации экономики России // Информационная безопасность регионов. - 2014. - № 4 (17). - С. 86-91.

14. Манахова И.В., Кадомцева С.В. Конвергенция моделей социального государства на новой технологической основе // Вестник Саратовского государственного социально-экономического университета. - 2015. - № 5 (59). - С. 12-16.

15. Быкова Е.С., Ежикова Н.А. Развитие интеллектуального потенциала предприятия // Вестник Пермского государственного технического университета. Социально-экономические науки. - 2010. - № 6. - С. 35-45.

\section{References}

1. Sushkova I.A. Novaia industrializatsiia natsional'noi ekonomiki: poniatie, usloviia, podkhody [New industrialization of national economy: Concept, conditions, approaches]. Vestnik Saratovskogo gosagrouniversiteta im. N.I. Vavilova, 2014, no. 4, pp. 93-97.

2. Sushkova I.A. Mekhanizm neoindustrializatsii: metodologiia obosnovaniia [Neoindustrialization mechanism: methodology of justification]. Izvestiia Saratovskogo universiteta. Novaia seriia. Seriia Ekonomika. Upravlenie. Pravo, 2013, vol. 13, issue 4, part 2, pp. 656-661.

3. Sushkova I.A. Formirovanie innovatsionnogo vosproizvodstva - priznak i uslovie novoi industrializatsii [Formation of innovative reproduction - a sign and condition of a new industrialization]. Innovatsionnaia deiatel'nost', 2013, no. 4, vol. 27, pp. 73-79.

4. Sushkova I.A. Predposylki formirovaniia politiki neoindustrializatsii [The prerequisites for neoindustrialization policy formation]. Filosofiia khoziaistva. Al'manakh Tsentra obshchestvennykh nauk i ekonomicheskogo fakul'teta MGU im. M.V. Lomonosova, 2014, no. 6, vol. 96, pp. 139-148. 
5. Mau V. Ekonomicheskaia politika 2010 goda: v poiskakh innovatsii [Economic policy of 2010: In search of innovations]. Voprosy ekonomiki, 2011, no. 2, pp. 4-22.

6. Sushkova I.A. Perekhod k novoi modeli ekonomicheskogo razvitiia - osnova formirovaniia politiki neoindustrializatsii [Transition to a new model of economic development - the basis for neoindustrialization policy formation]. Predprinimatel'stvo, 2014, no. 2, pp. 94-103.

7. Sushkova I.A. Neoindustrial'naia politika: osnovy formirovaniia, faktory razvitiia [Non-industrial policy: Basics of formation and development factors]. Saratov, Nauka Publ., 2013, 238 p.

8. Plyshevskii B. Ob "ekonomike predlozheniia" (ee ideinye osnovy i tseli) [On the "supply-side economy" (its ideological foundations and goals)]. Ekonomist, 2012, no. 7, pp. 3-15.

9. Gubanov S. Neoindustrializatsiia Rossii i nishcheta ee sabotazhnoi kritiki [Russia's neoindustrialization and its sabotage criticism poverty]. Ekonomist, 2014, no. 4, pp. 3-32.

10. Mamaeva L.N. Innovatsionnoe predprinimatel'stvo v Rossii v usloviiakh sanktsii [Innovative entrepreneurship in Russia under the sanctions]. Vestnik Tverskogo gos. universiteta. Ekonomika i upravlenie, 2015, no. 4, pp. 59-64.

11. Sushkova I.A. Printsipy i problemy neoindustrial'nogo preobrazovaniia rossiiskoi ekonomiki [Principles and problems of Russian economy neo-industrial transformation]. Informatsionnaia bezopasnost' regionov, 2015, no. 4, vol. 21, pp. 67-75.

12. Mamaeva L.N. Investitsionnaia privlekatel'nost' Saratovskoi oblasti [Investment attractiveness of Saratov oblast]. Nauka $i$ obshchestvo, 2014, no. 4, vol. 19, pp. 17-20.

13. Sushkova I.A. Innovatsionnoe vosproizvodstvo kak ob"ektivnaia neobkhodimost' neoindustrializatsii ekonomiki Rossii [Innovative reproduction as an objective necessity of Russian economy neoindustrialization]. Informatsionnaia bezopasnost' regionov, 2014, no. 4, vol. 17, pp. 86-91.

14. Manakhova I.V., Kadomtseva S.V. Konvergentsiia modelei sotsial'nogo gosudarstva na novoi tekhnologicheskoi osnove [Convergence of the social state models on a new technological basis]. Vestnik Saratovskogo gosudarstvennogo sotsial'no-ekonomicheskogo universiteta, 2015, no. 5, vol. 59, pp. 12-16.

15. Bykova E.S., Ezhikova N.A. Razvitie intellektual'nogo potentsiala predpriiatiia [Intellectual potential development of an enterprise]. PNRPU Sociology and Economics Bulletin, 2010, no. 6, pp. 35-45.

Оригинальность $91 \%$

Получено 16.12.2016 Принято 11.01.2017 Опубликовано 30.09.2017 


\section{I.A. Sushkova}

\section{RUSSIAN NEO-INDUSTRIALIZATION:}

\section{INTERNAL BARRIERS ON THE WAY OF ITS IMPLEMENTATION}

The article justifies the relevance of neo-industrialization of the Russian economy. It considers the internal barriers on the way of neo-industrialization, which are primarily conditioned by the state of production forces and labour relations in the country. The author of the article claims that a positive solution to the problems is connected with the accuracy of decision-making, as well as the application of an adequate approach to the innovative neo-industrial course development. The author considers that building a new development model implies a prompt admission and implementation of the policy of neoindustrialization. The research analyzes the conditions and trends for the policy's implementation. It states the need to accelerate the transition to a new model of national economy and to improve the quality of corporate management. The paper proves the necessity to increase production efficiency and enhance the role of the government both at the marketing and industrial levels, as well as directing the flow of money for the development of industrial economic sector. The author claims the need to switch to the innovative type of the country's economy in order to continue the implementation of neoindustrialization process. This requires the new organization forms and business patterns of innovative activity. In order to overcome the neo-industrialization barriers, the government should radically change its attitude to preserving and augmenting its intellectual resources. In conclusion, the author claims that a consistent implementation of the policy can be reached by resolving the contradictions between the government institutions and private enterprises. It is assumed that Russia has the pre-conditions for overcoming the barriers of the economy's neo-industrialization.

Keywords: neo-industrialization, neo-industrialization policies, labour productivity, state industrial policy, industrial development, investments, innovative type of economic growth, innovative activity, corporate management, intellectual resources, human potential, national capital, financial flows, neoindustrial transformations, new economic model.

Irina A. Sushkova - Candidate of Economic Sciences, Associate Professor, Dept. of Economic Security, Saratov Socio-Economic Institute (Branch of the Russian Economic University n.a. G.V. Plekhanov), e-mail: irinasushkova60@mail.ru.

Received 16.12.2016 $\quad$ Accepted 11.01.2017 Published 30.09.2017 